\title{
Diez falacias sobre los problemas sociales de América Latina
}

\author{
Klíksberg, Bernardo*
}

\section{Resumen}

En general, en esta última década que cierra el milenio, la población de América Latina está clamando porque se den cambios por la vía democrática, y no por otra vía, que permitan enfrentar los profundos problemas sociales. Sobre esos problemas y cómo deben ser enfrentados, ha surgido la circulación profusa de ciertas falacias, lo que ha dado lugar a la adopción de políticas erróneas y a transitar por caminos que cada dia nos alejan de la salida posible. El objetivo de este trabajo es llamar la atención sobre esas falacias, con la finalidad de estimular la discusión y presentar algunas consideraciones sobre el efecto pernicioso que ellas han tenido en el diseño de políticas.

Palabras clave: Pobreza, políticas públicas, economía, eficiencia, América Latina.

\section{Ten Fallacies About Social Problems in Latinamerica}

\section{Abstract}

In general, over the last decade which closed the millenium, the population of Latin America has been demanding that changes be made through democratic processes, and not through any other measures, which would permit the resolution of profound social problems. As to the problems and how they should be resolved, there is a wide-spread circulation of certain fallacies, which has given place to the adoption of erroneous policies and the adoption of paths which lead us astray from the true solutions. The objective of this paper is to call attention to these fallacies for the purpose of stimulating discussion and to present certain considerations as to the pernicious effect that these fallacies have had on policy design.

Key words: Poverty, public policy, economic, efficiency, Latin America.

Recibido: 00-11-21. Aceptado: 00-11-30

Coordinador del Instituto Interamericano para el Desarrollo Social (INDES/BID). Profesor Honorario de la Universidad de Buenos Aires, Argentina. 


\section{Hora de escuchar a la gente}

¿Qué piensan los latínoamericanos sobre lo que está sucediendo en la región? Cuando se les pregunta algo tan concreto sobre si creian que están viviendo mejor o peor que sus padres, sólo un $17 \%$ dijo que mejor, la gran mayoría sentían que su situación haba desmejorado (Latín Barómetro, 1999). Esta respuesta evidencia un hondo sentimiento de descontento. Las mayorias tienen bien claro en el Continente cuales son las causas de su disconformidad. Se hallan bien conscientes de ellas. $Y$ distinguen perfectamente causas aparentes, de otras más profundas. Cuando se les interroga sobre si creen que la democracia es preferible a cualquier otro sistema de gobierno, muestran un apoyo masivo al sistema democrático y sus ideales. Dos terceras partes lo prefieren, y sólo un $20 \%$ siguen exhibiendo inclinaciones hacia el autoritarismo. Pero cuando se profundiza expresan que están fuertemente insatisfechos en como la democracia está funcionando en sus países. Sólo el $35 \%$ está satisfecho con su funcionamiento. En la Unión Europea para comparar la cifra es el $47 \%$, en Dinamarca el $84 \%$. Los latinoamericanos han elegido la democracia como forma de vida, y la respaldan consistentemente, pero "democráticamente" están fuertemente disconformes con su desempeño concreto.

Entre las causas de insatisfacción algunas son políticas, pero tienen un peso decisivo las económico-sociales. La gran mayoría considera que los problemas vinculados con la pobreza han empeorado. Se refieren a carencias en oportunidades de trabajo, acceso a salud, ac- ceso a educación de buena calidad, incertidumbre laboral, bajos sueldos. Agregan a ello temas como el agravamiento de la corrupción, la delincuencia, y el tráfico de drogas. Además, testimonian que sienten que ésta es una región donde existen grandes desigualdades, y resienten agudamente esa situación.

Los dos únicos paises donde los promedios de satisfacción con el desempeño del sistema democrático son mayores a los de la unión Europea, son Costa Rica y Uruguay, donde más del $60 \%$ de la población está satisfecha con su funcionamiento. Son dos paises que se caracterizan por tener los más bajos niveles de desigualdad de toda la región, y por haber desarrollado algunos de los más avanzados sistemas de protección social de la misma.

Las encuestas reflejan que la población esta clamando por cambios que permitan enfrentar los agudos problemas sociales a través de la democracia y no por otra vía.

Los avances en ese camino parecen encontrar obstáculos formidables en la región si se juzga por los limitados resultados alcanzados. Algunos tienen que ver con la existencia de fuertes intereses creados y de privilegios que obtienen beneficios del mantenimiento de la situación vigente. Otros con dificultades derivadas de la inserción económica de la región en la nueva economía internacional. Otros, con el funcionamiento defectuoso de instituciones y organizaciones básicas. A estos y otros añadibles, se suma la circulación profusa de ciertas falacias sobre los problemas sociales que llevan a la adopción de políticas erróneas, y a emprender caminos que alejan de la salida 
del largo túnel en que está sumida buena parte de la población. No son el único factor de retraso, pero claramente su peso muy fuerte en sectores con mucha influencia en la toma de decisiones obstruye seriamente la búsqueda de alternativas renovadoras, y el paso hacia una nueva generación de políticas económicas y sociales.

El objetivo de este trabajo es llamar la atención sobre estas falacias, para estimular la discusión amplia y abierta sobre las mismas, con vias a su superación.

Se presentan a continuación algunas de las principales falacias, se analizan algunos de sus efectos en el diseño de políticas, y se examina su consistencia. Se trata sobre todo de procurar ponerlas a foco, e invitar a una reflexión colectiva sobre ellas.

\section{Primera Falacia: \\ La Negación o la Minimización de la Pobreza}

Existe una intensa discusión metodológica sobre como medir la pobreza en la región. Sin embargo, a pesar de los resultados diversos que surgen de diferentes mediciones, los estudios tienden a coincidir en dos aspectos centrales: a) Las cifras de población ubicada por debajo del umbral de pobreza son muy elevadas; b) Existe una tendencia consistente al crecimiento de dichas cifras en los últimos 20 años. Las cifras se deterioran severamente en los ochenta, mejoraron discretamente en parte de los 90 , pero en los años finales de la década aumentaron significativamente. En su conjunto la pobreza es mayor en el 2000 a la que la región tenía en 1980, tanto en términos de número de pobres, como en el porcentaje que significan los pobres sobre la población total.

La CEPAL estima en su Panorama Social de América Latina 2000, que la población en situación de pobreza creció de 1997 hasta comienzos del 2000 de 204 millones a no menos de 220 millones. Analizando la estructura de la fuerza de trabajo en ocho paises de la región que comprenden el $75 \%$ de su población total (Brasil, Chile, Colombia, Costa Rica, El Salvador, México, Panamá y Venezuela) la CEPAL constata que el $75 \%$ de la población que tiene ocupación "percibe ingresos promedios que en la mayoría de los países no alcanzan por sí solos para sacar de la pobreza a una familia de tamaño y composición típica".

La evolución de la pobreza en América Latina puede verse en el Gráfico 1 según refiere el BID (1998).

Como puede observarse, desde los 80 se produce una firme elevación del número de personas que gana menos de dos dólares diarios. Verrier (1999) señala que en toda América Latina había entre 1970 y 1980 , cincuenta millones de pobres e indigentes, pero que en 1998 ya eran 192 millones. La Comisión Latinoamericana y del Caribe para el Desarrollo Social presidida por Patricio Aylwin (1995) considera que se hallan en pobreza "casi la mitad de los habitantes de América Latina y el Caribe".

Diversas mediciones nacionales señalan con las diferencias propias de cada realidad la extensión y profundidad de la pobreza. Un informe detallado sobre Centro América (PNUD-Unión Europa 1999) señala que son pobres el $75 \%$ de los guatemaltecos, el $73 \%$ de los hondu- 
reños, el $68 \%$ de los nicaragüenses, y el $53 \%$ de los salvadoreños. Las cifras relativas a la población indígena son aún peores. En Guatemala se halla por debajo de la línea de pobreza el $86 \%$ de la población indígena frente al $54 \%$ de los no indígenas. En Venezuela se estimaba la pobreza entre el 70 y el $80 \%$ de la población. En Ecuador en un $62.5 \%$. En Brasil se estima que el $43,5 \%$ de la población gana menos de dos dólares diarios, y que 40 millones de personas viven en pobreza absoluta. Aún en paises donde tradicionalmente las cifras de pobreza han sido bajas como en la Argentina, el Banco Mundial ha estimado que está en pobreza casi la tercera parte de la población y el $45 \%$ de los niños. En las provincias más pobres como las del nordeste la tasa es del $48.8 \%$.

Uno de los tantos indicadores del grado de "rigidez" de la pobreza latinoamericana lo proporcionan las proyeccio- nes sobre niveles de educación e ingresos. La CEPAL (2000) afirma con base en ellas que "10 años de escolaridad parecen constituir el umbral mínimo para que la educación pueda cumplir un papel significativo en la reducción de la pobreza: si se tiene un nivel educativo inferior a 10 años de escolaridad y no se poseen activos productivos, son muy escasas las probabilidades de superar los niveles inferiores de ingreso ocupacional". El promedio de años de escolaridad en la región se ha estimado en 5.2, virtualmente la mitad del mínimo necesario para tener posibilidades de emerger de la pobreza.

Frente a estas realidades la alternativa lógica es partir de ellas, y tratar de encontrar vías innovativas para enfrentarlas. Sin embargo, en el discurso público latinoamericano de las dos últimas décadas, ha sido reiterada la tendencia de algunos sectores a optar por otra vía, la

\section{Gráfico 1}

Evolución de la pobreza en América Latina 1970-1995

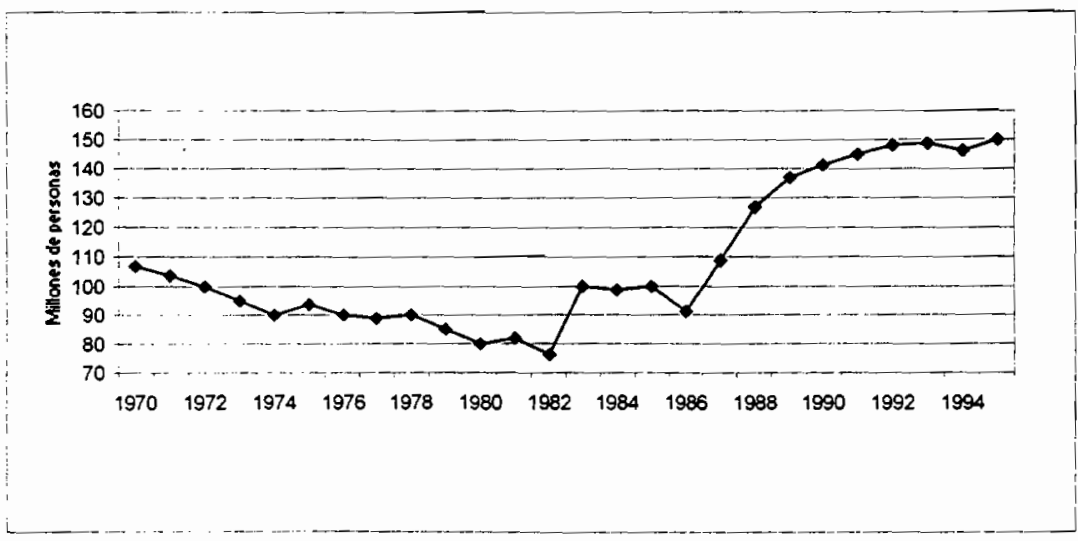

Fuente: BID, Informe de progreso económico y social, 1998.

Nota: Línea de pobreza de 2 dólares per cápita ajustado según año base 1985. 
negación o minimización del problema. La falacia funciona a través de diversos canales. Uno es la relativización de la situación. "Pobres hay en todos lados" acostumbraba a señalar un mandatario de un país latinoamericano frente al ascenso de las cifras de pobreza en su pais durante su período gubernamental. En materia económico-social lo conveniente es siempre desagregar los datos, $y$ tener una perspectiva comparada e histórica para saber cual es la situación real. Los países desarrollados tienen efectivamente también porcentajes de población ubicados por debajo de la línea de pobreza. Pero hay varias diferencias. Por una parte las cifras difieren muy fuertemente.

La población pobre es normalmente en ellos menor al $15 \%$. Es muy diferente tener entre una sexta y una séptima parte de la población en situación de pobreza, a tener a casi la mitad de la población en ese estado. No sólo es una diferencia cuantitativa, es otra escala que implica considerables diferencias cualitativas. En los países desarrollados se habla de "islotes de pobreza", o de "focos de pobreza": En varias áreas de América Latina, es muy dificil reflejar la realidad con ese lenguaje. La pobreza es extensa, diversificada, $y$ tiene actualmente incluso una fuerte expresión en las clases medias, en donde el deterioro de sus bases económicas ha generado un estrato social en crecimiento denominado "los nuevos pobres". No hay "focos de pobreza" a erradicar, sino un problema mucho más amplio y generalizado que requiere estrategias globales.

Por otra parte, la comparación estricta podría llevar a identificar que la brecha es aún mucho mayor. Las líneas de pobreza utilizadas en los países desarrollados son mucho más altas que las empleadas normalmente en América Latina. Así entre otros la difundida tendencia a medir la pobreza considerando pobres a quienes ganan menos de 2 dólares diarios, es muy cuestionable. En todos los países de la región la línea de pobreza está muy por encima de esa cifra.

Otro pasaje usual del discurso negador, es la afirmación de "que pobres hubo siempre", por tanto no se entiende por qué tanto énfasis en la situación actual. Alli la falacia adquiere el tono de la historicidad. Uno de los razonamientos más utilizados cuando se trata de relativizar un problema grave, es quitarle el piso histórico. La pobreza ha existido en América Latina desde sus orígenes, pero el tema es ¿Cuáles son las tendencias presentes? ¿En qué dirección apuntan, van hacia su disminución, su estancamiento, o su incremento? En los últimos 20 años parecen haber suficientes evidencias para preocuparse. Los indicadores han experimentado un deterioro, con altibajos y variaciones nacionales, las cifras han ascendido. Son muy pocos los casos en donde ha habido reducciones de consideración.

La falacia de desconocer o relativizar la pobreza, no es inocua. Tiene severas consecuencias en términos de políticas públicas. SI hay pobres en todos lados, y los ha habido siempre ¿por qué dar al tema tan alta prioridad? Hay que atenuar los impactos, pero no asustarse. Basta con políticas de contención rutinarias. La política social no es la importante. Es una carga de la que no es posible desprenderse, pero como se trata de afrontar un problema que siempre existirá y todos 
los paises tienen, cuidado con sobreestimarla. El enfoque lleva a politicas sociales de muy bajo perfil, y a una desjerarquización de todo el área social. En algunas de las expresiones más extremas de la falacia, se procuró en la década pasada eliminar de agendas de reuniones relevantes, "pobreza" viéndola ya en sí como demasiado cargada de connotaciones.

Además de conducir a políticas absolutamente incapaces de enfrentar las realidades de pobreza, la falacia expuesta entraña un importante problema ético. No sólo no da soluciones a los pobres, lo que lleva a la perduración y acentuación de situaciones de exclusión humana antiéticas, sino que va aún más lejos; a través de la minimización y la relativización está cuestionando la existencia misma del pobre

\section{Segunda Falacia: La Falacia de la paciencia}

Con frecuencia el razonamiento explícito o implícito que se despliega frente a los problemas sociales por parte de sectores influyentes gira en derredor a la necesidad de una cierta "paciencia histórica". Se trata de etapas que deben sucederse las unas a las otras. Habrá una etapa de "ajustarse el cinturón", pero luego vendrá la reactivación y posteriormente ella se "derramará" hacia los desfavorecidos y los sacará de la pobreza. Lo social debe esperar, y se necesita entender el proceso, y guardar paciencia mientras las etapas se suceden. Independientemente del amplio cuestionamiento que hay actualmente sobre todo esta visión del proceso de desarrollo, queremos enfatizar aqui uno de sus ele- mentos. El mensaje que se esta enviando es de hecho, que la pobreza puede esperar. ¿Realmente puede esperar? La realidad indica que el mensaje tiene una falla de fondo; en muchísimos casos, los daños que pueden causar la espera son simplemente irreversibles, después no tendrán arreglo posible.

Veamos, una buena parte del peso de la pobreza recae en América Latina sobre los niños y los adolescentes. En 1997 según CEPAL (2000) el $58 \%$ de los niños menores de 5 años de la región eran pobres, 10 mismo sucedia con el $57 \%$ de los niños de 6 a 12 años, y con el $47 \%$ de los adolescentes de 13 a 19 años. Siendo en su conjunto los menores de 20 años el $44 \%$ de la población de la región, representaban en cambio el $54 \%$ de todos los pobres. Las cifras verifican que efectivamente como fue subrayado por UNICEF (1992) "en América Latina la mayoría de los pobres son niños y la mayoría de los niños son pobres".

Esa no es una situación neutra. Como lo subraya Peter Tonwsed "la pobreza mata". Crea factores de riesgo que reducen la esperanza de vida, y desmejoran sensiblemente la calidad de la vida. Los niños son los pobres de América Latina según lo visto, y al mismo tiempo por naturaleza los más vulnerables. Sobre esos niños pobres operan varios factores que son generadores entre otros aspectos de lo que se denomina "un alto riesgo alimentario", insuficiencias en lo más elemental $\sin$ la posibilidad que puedan alimentarse normalmente. Los resultados de déficit de este orden, causan daños múltiples. Entre ellos se estima que los primeros años de vida se desenvuelven buena parte de las capacidades cerebra- 
les. La falta de una nutrición adecuada genera daños de carácter irreversible. Investigaciones de UNICEF (1992) sobre una muestra de niños pobres, determinaron que a los cinco años la mitad de los niños de la muestra presentaban retrasos en el desarrollo del lenguaje, un $30 \%$ atrasos en su evolución visual y motora, y un $40 \%$ dificultades en su desarrollo general. La desnutrición causa asimismo déficit en el peso y talla de los niños y ello va a repercutir fuertemente en su desenvolvimiento. Entre los factores generadores de riesgo alimentario se hallan: la falta de recursos de la familia, el carácter monoparental de la misma, y la baja educación de las madres.

Existe una robusta correlación estadistica entre estos factores y la desnutrición infantil. En la América Latina actual los tres factores tienen significativa incidencia. Como se señaló, numerosas familias tienen ingresos menores a los imprescindibles, se estima que cerca de un $30 \%$ de los hogares están a cargo de madres solas, en su gran mayoría se trata de hogares humildes, y el nivel educativo de las madres pobres es muy bajo. La pobreza del hogar puede significar que muchas madres estarán a su vez desnutridas durante el embarazo. Es probable entonces que el hijo tenga anemia, déficit de macronutrientes esenciales, y bajo peso. Ello puede amenazar su misma supervivencia, o atentar contra su desarrollo futuro. Si además, la madre está sola al frente de la familia, tendrá que luchar muy duramente para buscar ingresos. Su posibilidad de dedicación al niño en las críticas etapas iniciales será limitada. El factor educativo influirá asimismo en aspectos muy concretos. Asi las madres con baja escolaridad, tendrán poca información sobre como manejarse apropiadamente respecto a la lactancia materna, como armar dietas adecuadas, como cuidar sanitariamente los alimentos, como administrar alimentos escasos. En 1999, en 10 de 16 países de la región un 40 a un $50 \%$ de los niños urbanos en edad preescolar formaban parte de hogares cuya madre no había completado la educación primaria. En las zonas rurales en 6 de 10 países analizados el porcentaje era de 65 a $85 \%$, en los cuatro restantes de 30 a $40 \%$. Si se toman solo los niños menores de 2 años de edad, en 1997 del 20 al 50\% de los niños de la gran mayoría de los paises vivían en hogares con un ingreso por miembro, inferior al $75 \%$ del valor de la línea de pobreza, y cuya madre no había completado la educación primaria.

La acción combinada de éstos y otros factores lleva al sombrio panorama que capta la CEPAL (2000): "Al año 2000 se estima que aproximadamente el $36 \%$ del total de niños menores de 2 años de América Latina están en situación de alto riesgo alimentario". Los cuadros nacionales son alarmantes en diversos paises. En Nicaragua estimaciones del Ministerio de Salud (1999), indican que el $59 \%$ de las familias cubren menos del $70 \%$ de las necesidades de hierro que requiere el ser humano; el $28 \%$ de los niños de menos de 5 años padecen anemias por el poco hierro que consumen. 66 niños de cada 100 tienen problemas de salud por falta de vitamina A. El $80 \%$ de la población nicaragüense consume solo 1700 calorías diarias cuando la dieta normal debería ser no menor a las 2125 calorías. En Venezuela un niño de 7 años de los estratos altos pesa promedio $24,3 \mathrm{kgs}$. y mide 
$1,219 \mathrm{~m}$. Uno de igual edad de los sectores pobres pesa solo $20 \mathrm{~kg}$ y mide 1,148 $\mathrm{m}$. Aun en países con tanto potencial alimentario como la Argentina las estadísticas informan que en el gran Buenos Aires, una de las áreas poblacionales principales, uno de cada cinco niños está desnutrido.

Muchos de los paises de la región tienen importantes posibilidades naturales de producción de alimentos. Sin embargo, como se ha visto, una tercera parte de los niños más pequeños está en inseguridad alimentaria pronunciada. Ello parece difícil de entender. Influyen factores como los que identifican la Organización Panamericana de la Salud (OPS) y la CEPAL en investigación conjunta (1998): "Se observa en casi todos los países de la región un incremento en enfermedades no transmisibles crónicas asociadas con alimentación y nutrición. Las medidas de ajuste implementadas por los países han afectado la disponibilidad nacional de alimentos y han tenido repercusiones negativas sobre el poder de compra de los grupos más pobres, amenazando la seguridad alimentaria".

Así como la falta de alimentación causa daños no reparables posteriormente lo mismo sucede con otras expresiones de la pobreza como los déficits que afrontan los desfavorecidos en la región en dos aspectos básicos: el agua potable, y la existencia de alcantarillado y sistemas de eliminación de excretas. Ambos elementos son decisivos para la salud. Amplios sectores de la población pobre tienen dificultades muy fuertes para obtener agua potable o tienen que comprarla a precios muy elevados. Asimismo carecen de instalaciones de alcantarilla- do adecuadas, lo que significará graves riesgos de contaminación a través de los mapas subterráneos, y de contaminación del medio ambiente inmediato a la vivienda. Según los cálculos de la OPS cerca de la tercera parte de la población de la región carece de agua potable y/o alcantarillado. El $30 \%$ de los niños menores de 6 años viven en viviendas $\sin$ acceso a las redes de agua potable, y el $40 \%$ en viviendas sin sistemas adecuados de eliminación de excretas. Cuando se analiza por paises se observan datos como los que siguen, los cuales describen los porcentajes de niños de menos de 5 años de edad que habitaban viviendas sin conexión a sistemas de evacuación por alcantarillado en 1998 (CEPAL, 2000): Paraguay $87 \%$, Bolivia $66 \%$, Brasil $59 \%$, Honduras $47 \%$, El Salvador $45 \%$, Venezuela $26 \%$, México $24 \%$. La acción de estos factores genera mortalidad infantil y riesgos graves de salud, como los contagios, $y$ las infecciones intestinales. En 11 paises la diarrea es una de las dos principales causas de muerte en niños de menos de un año.

Nuevamente se trata de daños de carácter irreparable. La falacia de la paciencia respeto a la pobreza, niega de hecho el análisis de la irreversibilidad de los daños. Lleva a políticas en donde bajo la idea de que las cosas se arreglarán después, no se da la prioridad que correspondería a cuestiones elementales para la supervivencia. Nuevamente, además de las ineficiencias que significan esas políticas en cualquier visión de largo plazo de una sociedad, hay una falta ética fundamental. Frente a la pobreza deberia aplicarse una "ética de la urgencia", no es posible esperar ante problemas tan vita- 
les como los descriptos. Esta falacia desconoce el carácter de urgencia de estas y otras carencias básicas.

\section{Tercera Falacia: con el crecimiento económico basta}

El pensamiento económico ortodoxo de gran difusión en la región lanza el mensaje básico de que todos los esfuerzos deben ponerse en el crecimiento. Dirige las miradas a los pronósticos sobre el aumento del producto bruto, y el producto bruto per capita.

Despierta las expectativas de que todo está bien si ellos crecen a un buen ritmo. Plantea explícitamente como se mencionó, que logradas metas importantes de crecimiento todo lo demás se resolverá. El mismo fluirá hacia abajo, a través del famoso efecto "derrame" y ello solucionará los "rezagos" que pudieran existir en el campo social.

El siglo $X X$, ha enseñado muy duramente una $y$ otra vez que el último juez que decidirá si las teorias sobre el desarrollo son válidas o no, no es su grado de difusión, sino lo que cuentan los hechos. Ellos han desmentido muy fuertemente que la realidad funcione como la ortodoxia supone que debería funcionar. Las promesas hechas a América Latina a comienzos de los 80 sobre lo que sucedería al aplicar el modelo convencional, no se cumplieron en la práctica. Describiendo los productos concretos de lo que llama la "forma de hacer economía", que "América latina escogió en los años recientes", señala Ricardo French Davis (2000): "EI resultado es una fuerte inestabilidad del empleo y la producción, una mayor diferenciación entre ricos y pobres, y un cre- cimiento promedio modesto: sólo 3\% en este decenio, y con una profunda desigualdad". Efectivamente los datos indican que el crecimiento fue muy discreto, no se derramó automáticamente, la desigualdad aumentó significativamente, la pobreza no se redujo.

¿Frente a este juicio de la realidad no correspondería revisar el razonamiento usual? Joseph Stiglitz (1998) sugiere que ha llegado la hora de hacerlo. Se refiere a la visión general, uno de cuyos componentes esenciales es la idea de que el crecimiento basta. Argumenta: "Muchos paises han aplicado las recomendaciones intelectualmente claras, aunque generalmente difíciles políticamente, del consenso de Washington. Los resultados no han sido sin embargo del todo satisfactorios. Esto tiene varias explicaciones. ¿Será porque algunos no siguieron correctamente las recetas económicas? Tal vez. Sin embargo yo argumentaria que la experiencia Latinoamericana sugiere que deberíamos reexaminar, rehacer, y ampliar los conocimientos acerca de la economía de desarrollo que se toman como verdad, mientras planificamos la próxima serie de reformas".

La experiencia de América Latina y otras regiones del globo, indica que el crecimiento económico es imprescindible, es muy importante tratar de aumentar el producto total o de una sociedad. Son fundamentales asimismo el desarrollo de las capacidades tecnológicas, de la competitividad, y un clima de estabilidad económica. Pero, enseña también que es simplificar extremadamente el tema del desarrollo y de sus dimensiones sociales, aventurar que el crecimiento económico sólo producirá los resultados necesarios. 
El informe del Banco Mundial sobre la pobreza 2000 , que expresa la política oficial de dicha institución, plantea la necesidad de pasar de una vez a una visión mas amplia de la problemática del desarrollo. Comentando su enfoque diferencial señala un influyente medio, el Washington Post (2000): "La publicación del Informe Mundial de desarrollo del banco Mundial representa un significativo disenso del consenso sostenido entre economistas, de que la mejor vía para aliviar la pobreza es impulsar el crecimiento económico, y que la única vía para hacerlo es a través de mercados libres y abiertos. El informe hace notar que aún una década después de que las economias planificadas de Europa oriental fueran desmanteladas y el comercio e inversión global alcanzaran niveles récord, $24 \%$ de la población mundial recibe ingresos menores a un dólar diario. La conclusión ineludible de acuerdo a los economistas y expertos en desarrollo del Banco es que mientras el crecimiento económico puede ser un ingrediente necesario para reducir la pobreza no lo puede hacer solo".

Otro informe posterior del Banco Mundial "La calidad del crecimiento" (2000) producido por otros equipos del mismo, plantea también vigorosamente el mismo tipo de argumento básico. Dice presentándolo Vinod Thomas Director del Instituto del Banco (2000): "La experiencia de los paises en desarrollo y también de los industrializados muestra que no es meramente más crecimiento sino mejor crecimiento lo que determina en qué medida aumenta el bienestar, $y$ el bienestar de quien. Países con ingresos y crecimiento similares han obtenido en las últimas tres décadas logros muy diferentes en educación, salud y protección del medio ambiente". Se está sugiriendo que es decisiva la estructura del crecimiento, sus prioridades, vias de desarrollo, sectores beneficiados.

La falacia de que el crecimiento basta, transmite la visión de que se estaría avanzando si el producto bruto per capita sube, y que las miradas deben estar puestas en el mismo. Naciones Unidas ha desarrollado en la última década un cuerpo conceptual ampliamente difundido internacionalmente "el paradigma del desarrollo humano", que ataca radicalmente este razonamiento. No sólo el crecimiento no basta, es necesario pero no alcanza, sino que corresponde iniciar una discusión mayor, preguntarnos cuándo realmente una sociedad avanza, y cuándo está retrocediendo. Los parámetros definitivos, es la sugerencia, debemos encontrarlos en qué sucede con la gente. ¿Aumenta o disminuye su esperanza de vida? ¿Mejora o desmejora su calidad de vida? La ONU diseñó un índice de desarrollo humano que ha venido perfeccionando año tras año, que incluye indicadores que reflejan la situación de todos los países del mundo en áreas como: esperanza de vida, población con acceso a servicios de salud, población con acceso a agua potable, población con acceso a servicios de disposición de excretas, escolaridad, mortalidad infantil, producto bruto per capita ponderado por la distribución del ingreso. Los ordenamientos de los paises del mundo según sus logros en desarrollo humano que viene publicando anualmente la ONU, a través del PNUD, 
muestran un cuadro que en diversos aspectos no coincide con el que deviene de los puros récord de crecimiento económico.

Las conclusiones resultantes, enfatizan que cuanto mejor sea el crecimiento y más recursos haya, se ampliarán las posibilidades para la sociedad, pero la vida de la gente que es el fin último no se puede medir por algo que es un medio, debe medirse por indices que reflejen lo que sucede en ámbitos básicos de la vida cotidiana.

La falacia de que el crecimiento basta, está en definitiva transformando un medio fundamental, pero solo un medio, en el fin último. Es necesario desmistificarla y retomar un debate a fondo sobre qué está sucediendo con el cumplimiento de los fines. Amartya Sen (1998), ilustra los límites de esta falacia analizando varias situaciones reales. Realiza la comparación que se refleja en el gráfico 2.

Como se observa, los tres primeros países de la figura, el Estado de Kerala en la India (de 33 millones de habitantes). China y Sri Lanka tenian un producto bruto per capita muy reducido. Los otros tres Sud África, Brasil, y Gabón tenían un producto bruto que multiplicaba cinco a quince veces el de los anteriores. Sin embargo, la población vivía mas años en los tres países pobres: $71 ; 69, y$ 72 versus $63 ; 66$ y 54 .

El crecimiento económico solo no era el factor determinante en uno de los indicadores más fundamentales para ver si una sociedad adelanta, el más básico, la esperanza de vida. ¿Qué otras variables intervenían en este caso? Sen identifica aspectos, como las políticas públicas que garantizaban en los tres primeros países un acceso mas extendido a insumos fundamentales para la salud como el agua potable, las instalaciones sanitarias, la electricidad, y la cobertura médica. Asimismo las mejores posibilidades en materia de educación, a su vez incidente en la salud. Junto a ello un aspecto central era la mejor distribución del ingreso en las tres primeras sociedades. Todo ello llevó a que los paises supuestamente más pobres en términos del ingreso, fueran más exitosos en salud y años de vida. Dice Sen, "Ellos han registrado una reducción muy rápida de las tasas de mortalidad y una mejora de las condiciones de vida, sin un crecimiento económico notable".

\section{Cuarta Falacia: La desigualdad es un hecho de la naturaleza y no obstaculiza el desarrollo}

El pensamiento económico convencional ha tendido a eludir una discusión frontal sobre la desigualdad y sus efectos sobre la economía. Se ha apoyado para ello con frecuencia en la sacralización de la $\mathrm{U}$ invertida de Kusnetz (1970). De acuerdo a la misma, la desigualdad es simplemente una etapa inevitable de la marcha hacia el desarrolio. En la primera fase de la misma se producen polarizaciones sociales, que después se van moderando y reduciendo. Algunos economistas convencionales más extremos llegan aun más lejos, y plantean que esa acumulación de recursos en pocas manos favorecerá el desarrollo al crear mayores capacidades de inversión.

Esta discusión tiene particular trascendencia para América Latina, porque 


\section{Gráfico 2}

Producto nacional bruto y esperanza de vida en países seleccionados, 1992

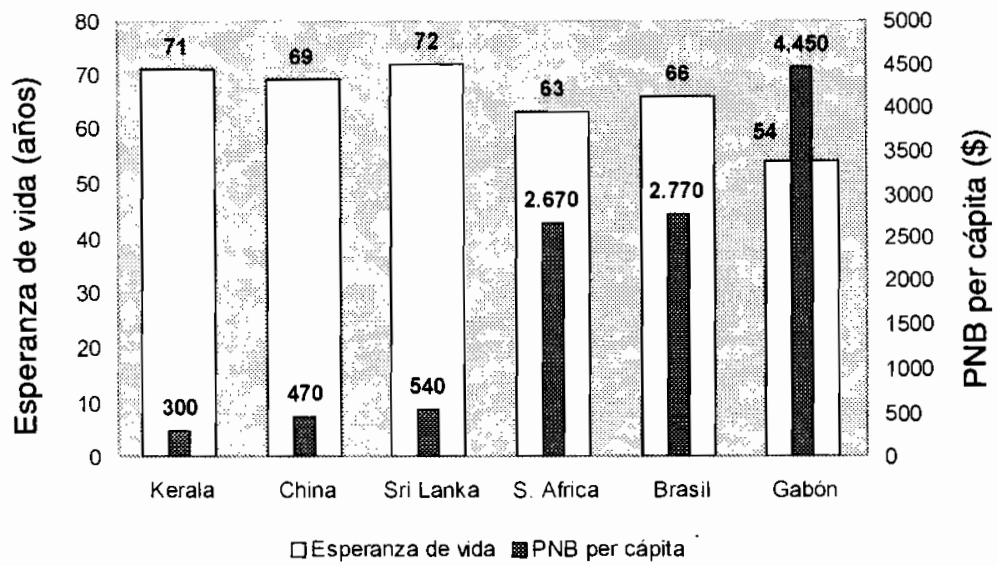

Fuente: Amartya Sen, "Mortality as indicator of economic success and failure". The Economic Journal, January 1998.

es considerada unánimemente la región más desigual del planeta. Si la tesis de los ortodoxos más duros fuera cierta, la región debería haber contado con tasas de inversión muy altas, dadas las "acumulaciones en pocas manos", que ha generado. No se ven. Tampoco parece ser una mera etapa del camino al desarrollo. En América Latina la desigualdad se ha instalado, y no solo que no se modera, sino que tiene una tendencia muy consistente a crecer, particularmente en las dos últimas décadas. La $U$ invertida parece no funcionar para la región.

En realidad Kusnetz (1970) nunca pretendió que fuera aplicable mecánicamente a los países no desarrollados. Como ha sucedido con frecuencia, algunos de sus supuestos intérpretes han hecho claro abuso de sus afirmaciones. Sus trabajos estuvieron referidos a la observación de USA, Inglaterra y Alemania en un período que comprendió desde la primera mitad del siglo XIX a la finalización de la primera guerra mundial. Advierte expresamente sobre el riesgo de generalizar las conclusiones que extrajo. Dice: "Es peligroso utilizar simples analogías; no podemos afirmar que puesto que la desigual distribución de la renta condujo en el pasado en Europa Occidental, a la acumulación de los ahorros necesarios para formar los primeros capitales, para asegurar el mismo resultado en los países subdesarrollados es preciso por to tanto mantener e incluso acentuar la desigualdad en la distribución de la renta". Y enfatiza en afirmación que en América Latina tiene mucho sentido hoy: "Es muy posible que los grupos que perciben rentas superiores en algunos de los países hoy subdesarrollados presenten una propensión de consumo mucho mayor y una propensión al ahorro mucho menor, que 
las que presentaban los mismos grupos de renta en los paises hoy desarrollados durante sus primeras fases de crecimiento".

Además de haber desvirtuado el pensamiento real del mismo Kusnetz, la falacia difundida respecto a la desigualdad, choca fuertemente con los datos de la realidad. La desigualdad latinoamericana se ha transformado a nivel internacional en un caso casi de laboratorio de los impactos regresivos de la desigualdad. Frente a la pregunta de por qué un continente con tantas potencialidades económicas y humanas, ha generado resultados económicos tan discretos, y déficits sociales tan agudos, una de las respuestas con creciente consenso científico es que uno de los factores fundamentales en contra ha sido el peso de la desigualdad, y su ascenso. Así señalan Birdsall, Ross y Sabot (1996) sobre la región, "la asociación entre un crecimiento lento y una elevada desigualdad se debe en parte al hecho de que esa elevada desigualdad puede constituir en sí misma un obstácuio para el crecimiento".

Están operando activamente en América Latina entre otros, cinco tipos de desigualdades. Uno es la inequidad en la distribución de los ingresos. El $5 \%$ de la población es dueña del $25 \%$ del ingreso nacional. Del otro lado, el $30 \%$ de la población tiene solo el $7.5 \%$ del ingreso nacional. Es la mayor brecha del planeta. Medida con el coeficiente Gini de inequidad en ingresos, América Latina tiene un 0.57 , casi tres veces el Gini de los países nórdicos. En promedio la mitad del ingreso nacional de cada país de la región va al $15 \%$ más rico de la población. En Brasil el $10 \%$ más rico tiene el $46 \%$ del ingreso, mientras que el $50 \%$ más pobre sólo tiene el $14 \%$ del mismo. En Argentina mientras que en 1975 el $10 \%$ más rico recibía ocho veces más ingresos que el $10 \%$ más pobre, en 1997 la relación se habia más que duplicado, era de 22 veces. Otra desigualdad acentuada es la que aparece en términos de acceso a activos productivos. La extremadamente inequitativa distribución de la tierra en algunos de los mayores países de la región, como Brasil y México, es una de sus expresiones. Una tercera desigualdad, es la que rige en el campo del acceso al crédito, instrumento esencial para poder crear oportunidades reales de desarrollo de pequeñas y medianas empresas. Hay en América Latina 60 millones de PYMES, que generan 150 millones de empleos. Sólo tienen acceso al $5 \%$ del crédito. Una cuarta inequidad es la que surge del sistema educativo. Los diferentes estratos socioeconómicos de los países alcanzan muy diversos récords en años de escolaridad. La deserción y la repetición provocadas por las condiciones socioeconómicas del hogar minan a diario la posibilidad de que los sectores pobres completen estudios. Según CEPAL (2000), en Brasil repetían los dos primeros grados de la escuela primaria el $41 \%$ de los niños del $25 \%$ de menores ingresos de la población, y en cambio sólo el $4.5 \%$ de los niños del $25 \%$ con mayores ingresos. Asimismo habian completado la escuela secundaria a los 20 años de edad, sólo el $8 \%$ de los jóvenes del $25 \%$ de menos ingresos, y en cambio el $54 \%$ del $25 \%$ de mayores ingresos. Tomando 15 países de la región (BID 1998) surgía que los jefes de hogar del $10 \%$ de ingresos mas altos tenían 11.3 años de educación, los 
del $30 \%$ más pobre solo 4.3 años. Una brecha de 7 años. Mientras que en Europa la brecha de escolaridad entre el $10 \%$ más rico y el $10 \%$ más pobre es de 2 a 4 años, en México es de 10 años. La desigualdad educativa va a ser un factor muy importante en la inequidad, en la posibilidad de conseguir trabajo y en los sueldos que se ganen. Los sectores desfavorecidos van a estar en muy malas condiciones al respecto por su débil carga educativa.

La fuerza de trabajo ocupada de la región presenta una marcada estratificación. Según la CEPAL (2000), hay un nivel superior que es el $3 \%$ de la población ocupada que tiene 15 años de escolaridad, un nivel intermedio que es el $20 \%$ de la fuerza de trabajo que tiene entre 9 y 12 años de escolaridad, y el $77 \%$ restante tiene sólo de 5.5 a 7.3 años de estudios en las ciudades y 2.9 en las zonas rurales. Una quinta y nueva cifra de desigualdad está surgiendo de las posibilidades totalmente diferenciadas de acceso al mundo de la informática y la Internet. La gran mayoría de la población no tiene los medios ni la educación para conectarse con el mismo. Forma parte asi de una nueva categoria de analfabetismo, el "analfabetismo cibernético".

Todas estas desigualdades generan múltiples efectos regresivos en la economía, la vida personal y familiar, y el desarrollo democrático. Entre otros, según lo demuestran numerosas investigaciones: reducen la formación de ahorro nacional, estrechan el mercado interno, conspiran contra la salud pública, impiden la formación en gran escala de capital humano calificado, deterioran la confianza en las instituciones básicas de las sociedades y en el liderazgo político. El aumento de la desigualdad es por otra parte una de las causas centrales del aumento de la pobreza en la región. Birdsall y Londoño (1998) han estimado econométricamente que su ascenso entre 1983 y 1995 duplicó la pobreza, que la misma hubiera sido la mitad de lo que fue si la desigualdad hubiera seguido en los niveles que tenía anteriormente, elevados pero menores.

La desigualdad latinoamericana no es un hecho natural propio del camino del desarrollo como lo pretende la falacia. Es la consecuencia de estructuras regresivas y políticas erradas que la han potenciado. Bárbara Stallings (1999) considera, que "las reformas económicas aplicadas en los últimos años han agravado las desigualdades entre la población" y subraya "se puede afirmar sin ninguna duda, que los noventa son una década perdida en cuanto a la reducción de las ya alarmantes diferencias sociales existentes en la región con mas desigualdad del mundo". Altimir (1994), después de analizar 10 países, plantea que "hay bases para suponer que la nueva modalidad de funcionamiento $y$ las nuevas reglas de política pública de estas economías, pueden implicar mayores desigualdades de ingreso". Albert Berry (1997) indica: "La mayoría de los países latinoamericanos que han introducido reformas económicas promercado en el curso de las últimas dos décadas han sufrido también serios incrementos en la desigualdad. Esta coincidencia sistemática en el tiempo de los dos eventos sugiere que las reformas han sido una de las causas del empeoramiento en la distribución". 
Por otra parte la otra dimensión de la falacia también es desmentida por la realidad. La desigualdad no se modera $o$ atenúa sola. Por el contrario la instalación de circuitos de desigualdad en áreas claves tiene una tendencia "contaminante", propicia la generación de circuitos similares en otras áreas. Lo ilustra entre otros casos, la dificultad, a pesar de todos los esfuerzos, en mejorar la situación educativa de la población pobre. Las desigualdades en otras áreas como ocupación e ingresos, conspiran contra las reformas educativas. Asimismo las desigualdades en educación van a reforzar, como se ha visto, las brechas en el mercado de trabajo. Los circuitos perversos de desigualdad muestran además una enorme capacidad reproductora. Se automultiplican. Sin acciones en contrario las polarizaciones tienden a crecer y ampliarse. Lo muestra la conformación creciente en numerosas sociedades de una dualidad central: incluidos y excluidos.

\section{Quinta Falacia: La desvalorización de la política social}

Un conocido Ministro de Economía de América Latina al ser preguntado sobre la política social en su país, contestó: "La única política social es la política económica".

Estaba reflejando toda una actitud hacia la política social que ha tenido hondas consecuencias en el Continente. Se ha tendido a verla como un complemento menor de otras políticas mayores como las que tienen que ver directamente con el desarrollo productivo, los equilibrios monetarios, el crecimiento tecnológico, la privatización etc. Le correspondería atenuar los impactos "transitorios" que las anteriores producen en la sociedad. Debería atacar focalizadamente los desajustes sociales más irritables para reducirlos. En el fondo desde este razonamiento se la percibe como una "concesión"a la política. Como la pobreza genera fuerte inquietud política, la política social haría el trabajo de "calmar los ánimos" y mostrar que se están haciendo cosas en ese frente, pero el corolario consecuente es: cuanto menos concesiones mejor. Los recursos destinados a lo social deberían ser muy acotados, y destinados a fines muy específicos.

Albert Hirschman llamó en una oportunidad a esta forma de abordar el tema: 'políticas pobres para pobres'. Da lugar a reducir lo social a metas muy estrechas, a constituir una institucionalidad social débil en recursos y personal, alejada de los altos niveles de decisión. Por otra parte, además altamente vulnerable, frente a reducciones presupuestarias, con muy escasa capacidad para defender su situación, y normalmente candidata preferida para los recortes. Por otra parte, esta visión supone en sí misma un cuestionamiento implícito de la legitimidad de la política social. Es distraer recursos de destinos más importantes, por "presión política".

Reflejando la situación, una ministro de lo social muy experimentada de un país latinoamericano narró al respecto a un auditorio internacional: "No nos invitaban al gabinete donde se tomaban las decisiones económicas más importantes. Después de muchos esfuerzos logramos se nos invitara. Claro, con voz pero sin voto". 
Considerar a la política social en estos términos: de una categoría inferior, concesión a la política, uso suboptimizante de recursos, conforma una falacia que esta afectando seriamente a la región.

En primer término, ¿Cómo puede relegarse a lo social en un contexto como el latinoamericano, donde casi una de cada dos personas están por debajo de la línea de la pobreza y expresan a diario de mil modos su descontento y protesta por esa realidad? Atender lo social no es una concesión, es en una democracia tratar de hacer respetar derechos fundamentales de sus miembros. Lo que está en juego es en el fondo, como plantea Naciones Unidas, una cuestión de derechos humanos violados. Corno resalta el Informe de Desarrollo Humano 2000 del PNUD: "La erradicación de la pobreza constituye una tarea importante de los derechos humanos en el siglo XXI. Un nivel decente de vida, nutrición suficiente, atención de salud, educación, trabajo decente y protección contra las calamidades no son simplemente metas del desarrollo, son también derechos humanos". Las políticas sociales son esenciales para la población en la región y estratégicas para la estabilidad misma del sistema democrático. Cuando se consulta a la población ella no pide que se reduzcan, estrechen, o eliminen sino todo lo contrario, exige masivamente que se refuercen, amplien, y se incorporen nuevas políticas.

En segundo lugar, es difícil sostener a inicios de este nuevo siglo que es una asignación de recursos de poca eficiencia. ¿Destinar recursos a asegurarse de que todos los niños terminen la escuela primaria, a elevar la tasa de completamiento de la secundaria, a desarrollar el sistema de educación superior, es ineficiente? Las mediciones econométricas dan resultados muy diferentes. La tasa de retorno en educación es una de las mas altas posibles para una sociedad. Actualmente la competitividad de los países está fuertemente ligada al nivel de capacitación de su población. Algunos de los países más exitosos del planeta en los mercados internacionales están exportando básicamente productos como "higth tech" totalmente basados en el capital educativo que han sabido desarrollar. La absorción de nuevas tecnologías, la innovación local a partir de ellas, la investigación y desarrollo, el progreso tecnológico, dependen todos de los niveles de educación alcanzados. Los cálculos demuestran así entre otros casos, que una de las inversiones más rentables macroeconómicamente que puede hacer un país, es invertir en la educación de niñas. Agregar años de escolaridad a las niñas desfavorecidas, va a aumentar su capital educativo, y a través de él, reducir las tasas de embarazo adolescente, de mortalidad materna, de mortalidad infantil, de morbilidad. Todos ellas están correlacionadas estadísticamente con los años de escolaridad de la madre.

¿En las condiciones latinoamericanas, extender la posibilidad de acceder a agua potable a toda la población es una inversión deficiente? El retorno de hacerlo será cuantioso en términos de salud pública, lo que repercutirá desde ya en la productividad de la economía.

En realidad toda la terminología utilizada está equivocada, y nuevamente vemos un error semántico no casual. Así como existian quienes no querian oír hablar de la palabra pobreza, en la falacia 
que desvaloriza la política social, se ha llevado a que toda la discusión al respecto se haga en términos de "gasto social". En realidad, no hay tal gasto. Bien gerenciados, los recursos para lo social constituyen en la gran mayoría de los casos inversiones de un alto retorno.

Hoy es difícil discutir las evidencias de que la inversión social genera capital humano, y que el mismo se transtorma en productividad, progreso tecnológico, y es decisivo para la competitividad. En realidad la política social, bien diseñada y eficientemente ejecutada, es un poderoso instrumento de desarrollo productivo. Corno lo sugiere Touraine (1997): "En vez de compensar los efectos de la lógica económica, la política social debe concebirse como condición indispensable del desarrollo económico".

En tercer término, se ha planteado la gravedad que tiene el tema de la desigualdad en América Latina. Superada la falacia que la niega o minimiza, ¿cómo se puede reducir? Una de las vías fundamentales posibles en una democracia, es una agresiva política social que amplíe fuertemente las oportunidades para los pobres, en campos cruciales. Deberá estar integrada entre otras por políticas que universalicen posibilidades de control de factores de riesgo claves en salud en la región, como el agua, el alcantarillado, la electricidad, el acceso a cobertura de salud, que actúen sobre los factores que excluyen a parte de la población del sistema educativo, que aseguren servicios públicos de buena calidad para todos. La política social puede ser una llave para la acción contra la desigualdad, proveyendo una base mínima de bienes y servicios indispensa- bles, y contribuyendo asi a abrir las oportunidades, y romper círculos perversos.

En lugar de una política social "cenicienta" como plantea la falacia, lo que América Latina necesita es una nueva generación de políticas sociales con mayúscula. Ello implica dar prioridad efectiva a las metas sociales en el diseño de las políticas publicas, procurar articular estrechamente las políticas económicas $y$ las sociales, montar una institucionalidad social moderna y eficiente, asignar recursos apropiados, formar recursos humanos calificados en lo social, fortalecer las capacidades de gerencia social, y jerarquizar en general esta área de actividad pública.

La metáfora que se escucha en toda la región describe bien la situación. Dice que la política social es actualmente la 'asistencia pública' que recoge los muertos y heridos que deja la política económica. La falacia examinada cultiva y racionaliza esta situación inaceptable. Se necesita una politica social que potencie el capital humano, base esencial de un desarrollo económico sostenido. Es un tema ético, político, y al mismo tiempo de lucidez histórica. Como lo anota Birdsall (1998): "es posible que las tasas de crecimiento de América Latina no puedan ser mas del 30 el $4 \%$, a distancia de las necesarias, en tanto no se cuente con la participación y el aporte de la mitad de la población que esta comprendida en los porcentajes más bajos de ingresos".

\section{Sexta Falacia: La maniqueización del Estado}

En el pensamiento económico convencional circulante se ha hecho un es- 
fuerzo sistemático de vastas proporciones para deslegitimar la acción del Estado. Se ha asociado la idea de Estado con corrupción, con incapacidad para cumplir eficientemente las funciones mas minimas, con grandes burocracias, con despilfarro de recursos. La visión se apoya en graves defectos existentes en el funcionamiento de las administraciones públicas en numerosos países de América Latina, pero fue mucho más allá de ello, y "maniqueizó" al Estado en su conjunto. Proyectó la imagen de que toda acción llevada en el terreno público sería negativa para la sociedad, y en cambio la reducción al mínimo de las políticas públicas, y la entrega de sus funciones al mercado la llevaría a un reino de la eficiencia y a la solución de los principales problemas económico-sociales existentes. Además creó la concepción de que existia una oposición de fondo entre Estado y sociedad civil, y había que elegir entre ambos.

Como en otros campos, hoy es posible mantener una discusión sobre el tema más allá de ideologías. El instrumental metodológico de las ciencias sociales actuales, aporta evidencias muy concretas que permiten establecer como funciona la realidad. La visión del Estado como solucionador de todos los problemas, "el Estado omnipotente", demostró ser errada. El Estado solo no puede hacer el desarrollo, y en América Latina la acción estatal ha presentado agudos problemas de burocratización, ineficiencia, y corrupción. Sin embargo, el proceso de eliminación de numerosas funciones del Estado, de reducción a niveles mínimos en muchos casos de sus capacidades de acción, como sucedió con frecuencia en las áreas sociales, el debilitamiento en general del rol de las políticas públicas, y la entrega de sus funciones al mercado, no llevó al reino ideal supuesto. Los problemas estructurales de las sociedades latinoamericanas y de otras del mundo en desarrollo siguieron agudizándose, la corrupción acompañó también con frecuencia a los procesos de privatización. Se identificó como una ley operante que siempre que hay un corrupto en el Estado hay a su vez un corruptor en el sector privado, es decir que el tema excede a cualquier simplificación. El funcionamiento sin regulación del mercado llevó a profundizaciones de las brechas, particularmente de las de inequidad. Se dio una marcada tendencia bajo las nuevas reglas de juego a la constitución de monopolios que significaron en la práctica la imposición de cargas muy pesadas a los consumidores, y a las pequeñas y medianas empresas, ahogando a estas últimas.

Pareciera que las dos polarizaciones han conducido a callejones sin salida. EI Estado solo no puede resolver los problemas, pero su minimización los agrava. Esa es la conclusión, entre muchas otras voces del Banco Mundial a fines de la pasada década. En su informe especial dedicado al rol del Estado (1998), resalta como una idea central que sin un Estado eficiente el desarrollo no es viable, y propone una serie de directrices orientadas a "reconstruir la capacidad de acción del Estado". Por su parte autores como Stiglitz (1998) y otros han llamado la atención sobre "las fallas del mercado", su tendencia a generar desigualdades, y a la cartelización para maximizar ganancias, y sus desvíos especulativos cuando no hay eficientes controles regulatorios, como se da en Estados tan debilitados por las reformas de las últimas dé- 
cadas como los de la región. Cáusticamente afirma una autoridad mundial en cómo gerenciar con eficiencia, Henry Mintzberg, (1996), respecto a la concepción de que se podía prescindir del Estado y la visión de que todo lo que se hace en el Estado es ineficiente y en el sector privado eficiente que: "el modelo representa el gran experimento de los economistas que nunca han tenido que gerenciar nada".

Hoy hay un activo retorno hacia la búsqueda de una visión más equilibrada en el debate internacional de punta sobre el tema del desarrollo y el rol del Estado. Imposible desconocer la importancia de las políticas públicas en un contexto histórico donde la segunda economía del mundo, Japón, está poniendo en marcha una tras otras sucesivas iniciativas de intervención activa del Estado para dinamizar la economía, la más reciente (Octubre 2000) inyectando 100.000 millones de dólares a tal efecto. Amartya Sen (1998), resalta especialmente el papel decisivo que ha jugado la política pública en el campo social, en algunas de las economías de mejor desempeño de largo plazo del mundo. Subraya: "De hecho muchos países de Europa Occidental han logrado asegurar una amplia cobertura de seguridad social con la prestación de atención en salud y educación pública de maneras hasta entonces desconocidas en el mundo. Japón y la región del Este de Asia han tenido un alto grado de liderazgo gubernamental en la transformación, tanto de sus economías como de sus sociedades; el papel de la educación y atención en salud pública ha sido el eje fundamental para contribuir al cambio social y económico en el mundo entero ( $y$ en forma bastante espectacular en el Este y Sudeste Asiáticos)".

Un área totalmente decisiva para la economía y la sociedad es la de la salud. Toda sociedad democrática tiene la obligación de garantizar el derecho a la atención en salud a sus miembros, es el derecho más básico. Asimismo mejorar los niveles de salud de la población tiene todo orden de impactos favorables sobre la economía, entre muchos otros aspectos en reducción de horas de trabajo perdidas por enfermedad, aumento de la productividad laboral, descenso de costos ligados a enfermedades, etc. El reciente informe sobre la salud mundial 2000 de la Organización Mundial de la Salud (OMS 2000) establece el primer ranking de los países del mundo según el desempeño de sus sistemas de salud. Entre otros construye un índice muy significativo para esas mediciones: los años promedio que una persona vive con buena salud, sin enfermedades. A la cabeza de la tabla se hallan países como Japón 74.5 años, Suecia 73, Canadá 72, Noruega 71.7. En todos esos países el Estado tiene una participación fundamental habiendo construido una amplísima red de protección. En Japón el gasto público es el $80.2 \%$ del gasto total en salud, en Suecia el $78 \%$, en Noruega el $82 \%$, en Canadá el $72 \%$. El gasto público per capita en salud sobrepasa en todos ellos los 1300 dólares anuales. El contraste con la actual situación en diversos países latinoamericanos es muy marcado. El gasto público per capita en salud es en Brasil 208 dólares, en México 172, en Pení 98. Los años de vida saludable promedio solo llegan en Brasil a 59. Dicho país es una de las mayores potencias industriales del mundo. En cambio, cuando se lo busca en las tablas de desempeño de los sistemas de salud de la OMS figura en el lugar número 125. 
El carácter crucial de la acción estatal en campos claves como salud y educación, desde ya de una acción bien gerenciada y transparente, surge con toda fuerza de una investigación reciente (Dunes, 2000) que muestra qué sucede cuando se fijan como política arancelar los servicios en áreas de población pobre bajo la idea de "compartir costos"y de "financiamiento comunitario", reduciendo así las responsabilidades del Estado. En Tanzania, siguiendo condicionalidades del Banco Mundial, se introdujeron aranceles en educación primaria. El resultado según índica la Iglesia Evangélica Luterana de Tanzania fue un inmediato descenso en la asistencia a la escuela, y los ingresos totales de las mismas fueron la mitad de los previstos. En Zimbawe la condicionalidad se centró en que debían cobrar aranceles en los servicios de salud, pero que los pobres estarian exceptuados de ello. Una evaluación del mismo Banco Mundial concluyó, que sólo 20\% de los pobres pudieron conseguir los permisos de exención necesarios. En Ghana, al imponer aranceles en la escuela, el $77 \%$ de los niños de la calle de Accra que asistían a las escuelas, las abandonaron.

La falacia de la maniqueización del Estado lleva a consecuencias muy concreta; al deslegitimar su acción deja abierto el terreno para su debilitamiento indiscriminado, y la desaparición paulatina de políticas publicas firmes en campos cruciales como los sociales. Causa así daños irreparables a vastos sectores de familias, aumenta la pobreza y la desigualdad, y limita las posibilidades de un crecimiento sostenido. Los datos de la realidad sugieren que hay otro camino. En algunos de los países más exitosos económica y socialmente del mundo, uno de los pilares de sus economías es un Estado activo de alta eficiencia. Una de sus características centrales, contradice uno de los ejes de la falacia. Es un Estado coordinado estrechamente con la sociedad civil. La falsa oposición Estado-Sociedad civil que preconiza la falacia como un hecho, es desmentida en ellos. Los lazos de cooperación son multiplisimos, y surge una acción integrada. También en América Latina misma algunas de las sociedades con mejores cifras de equidad, menor pobreza, y mejores tasas de desarrollo humano tuvieron como base de esos logros a Estados bien organizados, con burocracias consideradas eficientes, como Costa Rica, Uruguay, y el Chile democrático. Es imprescindible reformar y mejorar la eficiencia estatal y erradicar la corrupción. Pero para ello es necesario avanzar en otra dirección totalmente distinta a la de la falacia. No satanizar al Estado, sino ir construyendo administraciones publicas descentralizadas, transparentes, abiertas a la participación comunitaria, bien gerenciadas, con carreras administrativas estables fundadas en el mérito.

\section{Séptima Falacia: La incredulidad sobre las posibilidades de aporte de la sociedad civil}

El pensamiento económico circulante envía a veces explícitamente y con frecuencia implícitamente un profundo mensaje de desvalorización del posible rol que puede jugar la sociedad civil en los procesos de desarrollo y en la resolución 
de los problemas sociales. Su énfasis esta totalmente volcado en el mercado, la fuerza de los incentivos económicos, la gerencia de negocios, la maximización de utilidades como motor del desarrollo, las señales que pueden atraer o alejar al mercado. El mundo de la sociedad civil es percibido como un mundo secundario, de segunda línea respecto a lo que sucede en el "mundo importante" conformado por los mercados. De ese enfoque van a surgir políticas públicas de apoyo muy limitado, casi "simbólico" y por "cortesía" a las organizaciones de la sociedad civil, y una desconfianza fuerte a depositar en ellas responsabilidades realmente relevantes.

La falacia razona en términos de una dualidad básica: Estado versus mercado. En los hechos la situación es mucho más matizada. Existe un sinnúmero de organizaciones que no son ni lo uno, ni to otro. Fueron creadas con finalidades distintas, los actores sociales que se hallan tras ellas son otros, y las metodologías que utilizan no son de Estado ni de mercado. Este mundo comprende entre otras: las organizaciones no gubernamentales en continuo crecimiento en América Latina que han sido denominadas con frecuencia el tercer sector y que realizan múltiples aportes en el campo social; los espacios de interés público que son fórmulas especiales muy utilizadas en los países desarrollados en donde numerosas Universidades, y hospitales han sido fundados por ellos, se trata de emprendimientos de largo plazo animados por numerosos actores públicos y privados; modelos económicos que no son típicos de mercado como las cooperativas que tienen alta presencia en diversos campos; y el amplísimo movimiento de lu- cha contra la pobreza desarrollado en toda la región por las organizaciones religiosas, cristianas, protestantes, y judías que está en primera línea de la acción social. La realidad no es solo Estado y mercado como pretende la falacia. Incluso algunas de los modelos de organización y gestión social y general más efectivos de nuestro tiempo fueron desarrollados en esta vasta área diferente de ambos.

Todas estas organizaciones tienen un gran peso y una fuerte participación en la acción social en el mundo desarrollado. Recaudan recursos considerables, se les delegan funciones crecientes por parte del Estado, están interrelacionadas con la acción publica de múltiples modos están basadas fuertemente en trabajo voluntario. Movilizan miles y miles de personas que dedican anónimamente considerables horas a llevar adelante sus programas. Hacen aportes importantes al producto bruto nacional con trabajo no remunerado en países como Canadá, Holanda, Suecia, Noruega, Dinamarca, España, Israel y otros. Así, en Israel que figura entre los primeros del mundo en esta materia, una de cuatro personas hace trabajos voluntarios semanalmente, produciendo bienes y servicios de carácter social, constituyendo parte del personal paramédico en los hospitales, ayudando a personas discapacitadas, a ancianos, familias desfavorecidas, y otros sectores con dificultades. También ha aumentado en el mundo desarrollado la participación empresarial en el apoyo a la acción social de la sociedad civil. Las contribuciones e iniciativas empresarias de solidaridad se han incrementado, y la asunción de su responsabilidad social ha pasado a formar parte creciente de legitimidad misma de la empresa. La aseveración de hace 
años de Milton Friedman el guru de la Escuela de Chicago, de que la única responsabilidad de la empresa privada es producir utilidades a sus accionistas, ha sido refutada constantemente por empresarios prominentes, y es hoy rechazada masivamente por la opinión publica de los países desarrollados.

En América Latina la situación tiende a ser muy diferente. Existe un inmenso potencial de trabajo voluntario que de ser adecuadamente convocado y de crearse condiciones propicias podría cumplir roles de gran significación. Esforzadamente sectores de la sociedad civil están tratando de movilizarlo y surgen permanentemente múltiples iniciativas. Pero todo ello es a pesar de las desconfianzas y la incredulidad que surge del razonamiento desvalorizador, que alimenta a su vez gruesos errores en las politicas. No hay así entre otros aspectos apoyos públicos firmes a las iniciativas de la sociedad civil de acción social, y los incentivos fiscales son muy reducidos. Asimismo, el movimiento de responsabilidad social empresarial es débil y los aportes muy reducidos comparativamente. La proporción de las ganancias empresarias dedicadas a fines de interés público es mucho menor a la de los paises avanzados. Es notable el trabajo que aun con todas estas limitaciones llevan adelante numerosas organizaciones, entre ellas las de fe antes mencionadas, para lograr ayudar a las dificultades de supervivencia de extendidos sectores de la población
En el fondo lo que el pensamiento económico convencional está haciendo a través de su desvalorización de las posibilidades de la sociedad civil, es cerrar el paso a la entrada misma del concepto de capital social. Múltiples investigaciones de los años recientes desde los primeros estudios de Putnam y Coleman, hasta los efectuados en diversas realidades nacionales de todo el planeta, demuestran que hay factores cruciales para el desarrollo que no tenían lugar en el pensamiento económico ortodoxo como los agrupados en la idea de "capital social". Tales: el clima de confianza entre las personas de una sociedad y hacia sus instituciones y líderes, el grado de asociatividad, es decir, la capacidad de crear esfuerzos asociativos de todo tipo, y el nivel de conciencia civica, la actitud hacia los problemas colectivos desde cuidar el aseo en los lugares públicos hasta pagar los impuestos. Estudios del Banco Mundial atribuyen al capital social y el capital humano dos terceras parte del crecimiento económico de los paises, y diversas investigaciones dan cuenta de los significativos impactos del capital social sobre la performance macroeconómica, la productividad microeconómica, la gobernabilidad democrática, la salud publica, y otras dimensiones ${ }^{1}$.

Desarrollar el capital social significa fortalecer la sociedad civil por medio de políticas que mejoren la confianza, que según dicen los mismos estudios, en sociedades polarizadas es muy fuertemente erosionada por la desigualdad. También implica social y sus impactos en Bernardo Kliksberg "El capital social y la cultura. Claves olvidadas del desarrollo". Instituto de Integración Latinoamericana, INTAL/BID, Buenos Aires, 2000. 
propiciar el crecimiento de la asociatividad, y contribuir a hacer madurar la conciencia cívica. El razonamiento económico convencional ha estado aferrado a ideas muy estrechas sobre los factores que cuentan, que no consideran estos elementos, o que los relegan. Tras la falacia de la incredulidad sobre la sociedad civil, se halla un rechazo más amplio a la idea de que hay otros capitales a tener en cuenta, como el social. Un cerrado "reduccionismo economicista" obstruye el paso a ampliar la visión del desarrollo con su Incorporación y a extraer las consecuencias consiguientes en términos de políticas de apoyo al fortalecimiento y potenciación de las capacidades latentes en la sociedad civil.

\section{Octava Falacia: \\ La participación; sí, pero no}

La participación de la comunidad en forma cada vez más activa en la gestión de los asuntos públicos surge en esta época como una exigencia creciente de las grandes mayorías de la sociedad en América Latina y otras regiones. Los avances de la democratización, producto de largas luchas históricas de los pueblos, han creado condiciones de libre organización y expresión, que han disparado esta "sed" de participación. Por otra parte existe hoy una convalidación mundial creciente de la superioridad en términos de efectividad de la participación comunitaria, sobre las formas organizativas tradicionales de corte vertical, o burocrático. En el campo social ello es muy visible. Los programas sociales hacen mejor uso de los recursos, logran mejor sus metas, y crean autosustentabilidad si las comunidades pobres a las que se desea favorecer participan desde el inicio y a lo largo de todo su desarrollo y comparten la planificación, la gestión, el control y la evaluación. Señala al respecto Stern, el economista jefe del Banco Mundial, resumiendo múltiples estudios de la institución (2000): "A lo largo del mundo, la participación funciona: las escuelas operan mejor si los padres participan, los programas de irrigación son mejores si los campesinos participan, el crédito trabaja mejor si los solicitantes participan. Las reformas a nivel de los países son mucho más efectivas si son generadas en el país y manejadas por el país. La participación es práctica y poderosa"2.

Dos recientes trabajos: "Superando la pobreza humana" del PNUD (2000) $y$ "The voices of the poor" del Banco Mundial (2000), basado en una gigantesca encuesta a 60.000 pobres de 60 paises, llegan a similar conclusión en términos de políticas: es necesario dar prioridad a invertir en fortalecer las organizaciones de los propios pobres. Ellos carecen de "voz y voto" real en la sociedad. Fortalecer sus organizaciones, les permitiría participar en forma mucho más activa y recuperar terreno en ambas dimensiones. Se propone entre otros aspectos: facilitar su constitución, apoyarlas, dar posibilidades en Bernardo Kliksberg "Seis tesis no convencionales sobre participación" en Revista Venezolana de Gerencia, Año 3, No. 6. Diciembre 1998. 
de capacitación a sus lideres, fortalecer sus capacidades de gestión.

En América Latina el discurso político ha tendido a reconocer crecientemente a la participación. Seria claramente antipopular enfrentar la presión proparticipación $\tan$ fuerte en la sociedad, y con argumentos tan contundentes a su favor. Sin embargo, los avances reales en cuanto a la implementación efectiva de programas con altos niveles de participación comunitaria son muy reducidos. Siguen predominando los programas "llave en mano", e impuestos verticalmente, donde los decisores o diseñadores, son los que saben y la comunidad desfavorecida debe acatar sus directivas, $y$ ser sujeto pasivo de los mismos. También son usuales los programas en donde se hacen fuertes apelativos a que se trata de programas participativos, cuando en realidad hay un mínimo contenido real de intervención de la cornunidad en la toma de decisiones. El discurso dice sí a la participación en la región, pero los hechos con frecuencia dicen no.

Los costos de esta falacia son muy fuertes. Por un lado se están desechando enormes energías latentes en las comunidades pobres. Cuando se les moviliza como sucedió en experiencias latinoamericanas mundialmente reconocidas como Villa el Salvador en el Perú, las escuelas Educo en el Salvador, o el presupuesto municipal participativo en Porto Alegre $^{3}$, los re- sultados son sorprendentes. La comunidad multiplica los recursos escasos, sumando a ellos incontables horas de trabajo, y es generadora de continuas iniciativas innovativas. Asimismo la presencia de la comunidad es uno de los pocos medios probados que previene efectivamente la corrupción. El control social de la comunidad sobre la gestión es una gran garantia al respecto, que se pierde al impedir la participación. Por otra parte el divorcio entre el discurso y la realidad es claramente percibido por los pobres, y lo resienten con descontento y frustración. Se limitan así las posibilidades de programas donde se ofrezca participación genuina porque las comunidades están "quemadas"al respecto por las falsas promesas.

El si pero no, esta basado en resistencias profundas a que en definitiva realmente las comunidades pobres participen, que se distrazan ante su ilegitimidad conceptual, política, y ética. Ha llegado la hora en la región de ponerlas a foco y enfrentarlas.

\section{Novena Falacia: La elusión ética}

El análisis económico convencional sobre los problemas de América Latina escabulle normalmente la discusión sobre las implicancias éticas de los dife-

3 El caso de Villa El Salvador es analizado en detalle por Carlos Franco en su trabajo "La experiencia de Villa EI Salvador: del arenal a un modelo social de avanzada", incluido en la obra Bernardo Kliksberg "Pobreza, un tema impostergable. Nuevas respuestas a nivel mundial", Fondo de Cultura Económica, Buenos Aires, Caracas, cuarta edición 1997. Sobre el caso del presupuesto municipal participativo en Porto Alegre puede verse: Zander Navarro "La democracia afirmativa y el desarrollo redistributivo: el caso del presupuesto participativo en Porto Alegre, 
rentes cursos de acción posibles. Pareciera que se está tratando un tema técnico mas, de carácter neutro, donde solo deben predominar razonamientos costobeneficio para resolverlo. La situación es muy distinta. El tema tiene que ver con la vida de la gente y las consideraciones éticas deberian estar por ende absolutamente presentes. De lo contrario se está cayendo en el gran riesgo sobre el que previene uno de los mayores filósofos de nuestra época, Charles Taylor (1992), quien plantea que hay una acusada tendencia a que la racionalidad técnica, la discusión sobre los medios, reemplace a la discusión sobre los fines. La tecnología es un medio para lograr fines, que a su vez deben ser objeto de otro orden de discusión. Si la discusión sobre los fines desaparece como puede estar sucediendo previene Taylor, y la racionalidad tecnológica predomina sobre la racionalidad ética, los resultados pueden ser muy regresivos para la sociedad. En la misma dirección señaló recientemente otro destacado pensador Vaclav Havel, Presidente de la República Checa (2000) "es necesario reestructurar el sistema de valores en que nuestra civilización descansa", y advirtió que los países ricos, los llamó "euroamericanos", deben examinar su conciencia. Ellos dijo, han impuesto las orientaciones actuales de la civilización global y son responsables por sus consecuencias.

Estas voces prominentes sugieren un debate a fondo sobre los temas éticos del desarrollo. El llamado tiene raíces en realidades intolerables. La ONU (2000) llama la atención sobre la imprescindibilidad de un debate de este orden en un mundo donde perecen a diario $30.000 \mathrm{ni-}$ ños por causas evitables imputables a la pobreza. Dice que se reacciona indignamente y ello es correcto, frente a un solo caso de tortura, pero se pasa por alto a diario esta aniquilación en gran escala. EI Fondo de Población Mundial (2000) resalta que mueren anualmente 500.000 madres durante el embarazo, muertes también en su inmensa mayoria evitables y ligadas a falta de atención médica. $99 \%$ de ellas, se producen en los llamados países en desarrollo.

En América Latina, resulta imprescindible debatir entre otros, temas como: ¿Qué pasa con las consecuencias éticas de las políticas? ¿Cuál es la eticidad de los medios empleados? ¿es éticamente lícito sacrificar generaciones? ¿Por qué los más débiles como los niños, y los ancianos son los más afectados por las politicas aplicadas en muchos países?, y la destrucción de familias que está generando la pobreza? $Y$ otras cuestiones similares. América Latina es una región donde, como se ha visto, la mayoría de los niños son pobres, donde miles y miles de niños viven en las calles marginados por la sociedad, y donde mientras la tasa de mortalidad de niños menores de cinco años era en 1997 en Canadá de 6.9 cada 1000, llegaba en Bolivia a 82.8, en Ecuador a 57.7, en Brasil a 45.9, en México a 36.4 (Organización Panamericana de la Salud 2000). En América Latina, el $17 \%$ de los partos se producen sin asistencia

Brasil". Incluido en Edmundo Jarquin, y Andrés Caldera (comp.), "Programas sociales, pobreza y participación ciudadana", BID, Washington, 2000. 
medica de ningún tipo con los consiguientes efectos en términos de mortalidad materna que es cinco veces mayor a la de los países desarrollados, y sólo se hallan cubiertos previsionalmente el $25 \%$ de las personas de edad mayor.

Surgen de todo ello problemas éticos básicos: ¿Qué es más importante? ¿Cómo asignar recursos? ¿No deberían reestudiarse las prioridades? ¿No hay políticas que deberían descartarse por su efecto "letal" en términos sociales?

Cuando se denuncia la debilidad de la falacia que elude la discusión ética, ella toma con frecuencia el rostro del "pragmatismo". Arguye, es imposible discutir de ética, cuando no hay recursos. Sin embargo, más que nunca cuando los recursos son escasos debería debatirse a fondo sobre las prioridades. En los paises en que ese debate se libra, los resultados suelen ser muy distintos en términos de prioridades y de resultados sociales, a aquellos en donde se elude. Cuanto más recursos existan mejor, y se debe hacer todo lo posible para aumentarlos, pero puede haber más y seguir asignados bajo los patrones de alta inequidad propios de América Latina. La discusión sobre las prioridades finales es la única que garantiza un uso socialmente racional de los recursos. La Comisión Latinoamericana y del Caribe presidida por $\mathrm{Pa}$ tricio Aylwin (1995) realizó un análisis sistemático para la Cumbre social mundial de Copenhague sobre que recursos hacian falta para solventar las brechas sociales más importantes de la región. Concluyó que no son tan cuantiosos como se supone imaginariamente, y que una parte importante de ellos pueden obtenerse reordenando prioridades, tortaleciendo una sistema fiscal progresivo y eficiente, y generando pactos sociales para aumentar los recursos para áreas criticas.

En un artículo cercano en el New York Times plantea un renombrado filosofo: Peter Singer (1999) que no es posible que los estratos prósperos de las sociedades ricas se libren de la carga de conciencia que significa la convivencia con realidades masivas de abyecta pobreza y sufrimiento en el mundo, y que deben encarar de frente su situación moral. Su sugerencia es totalmente extensiva a los estratos similares de América Latina.

\section{Décima Falacia: No hay otra alternativa}

Una argumentación preferida en el discurso económico ortodoxo es la alegación de que las medidas que se adoptan son las únicas posibles. No habria otro curso de acción alternativo. Por tanto los graves problemas sociales que crean son inevitables. La larga experiencia del siglo $X X$ es plena en fracasos históricos de modelos de pensamiento que se autopresentaron como el "pensamiento único". Parece demasiado complejo el desarroIlo, como para poder pensar que solo hay una sola vía. Por otra parte en diferentes regiones del globo los hechos no han favorecido al "pensamiento único". Resumiendo la situación dice William Pfaff (2000): "El consenso intelectual sobre las políticas económicas globales se ha roto". En la misma dirección, refiejando la necesidad de buscar nuevas vias, opina Felix Rohatyn (2000) actual Embajador de USA en Francia: "Para sostener los beneficios (del actual sistema económico) en EE.UU. y globaimente tenemos 
que convertir a los perdedores en ganadores. Si no lo hacemos, probablemente todos nosotros nos convertiremos también en perdedores". Amartya Sen (2000) a su vez destaca: "Ha habido demostraciones recientemente no solo frente a las reuniones financieras internacionales sino también en forma de protestas menos organizadas, pero intensas en diferentes capitales, desde Jakarta y Bangkok hasta a Abidjan y México. Las dudas acerca de las relaciones económicas globales continúan viniendo de diferentes confines del planeta, y hay suficiente razón para ver estas dudas acerca de la globalización como un fenómeno global, son dudas globales no una oposición localizada".

El clamor por cambios en las reglas de juego globales que afectan duramente a los países en desarrollo es muy intenso. Comprende una agenda muy amplia desde temas por los que ha clamado el Papa Juan Pablo II poniéndose a la cabeza de un vasto movimiento mundial que exige la condonación de la deuda externa para los países más pobres, pasando por el reclamo por las fuertes barreras a los productos de los países en desarrollo, hasta el tema muy directo de que la ayuda internacional al desarrollo ha bajado y está en su punto menor en muchas décadas. El Presidente del Banco Mundial Wolfensohn (2000) ha calificado a este hecho como "un crimen". Ha destacado que es "ceguera de los países ricos que destinan sumas insignificantes a la ayuda al desarrollo, no se dan cuenta de lo que está en juego". Planteando la necesidad de una política global alternativa señala el PNUD (2000): Que se debe "formular una nueva generación de programas centrados en hacer que el crecimiento sea mas propicio a los pobres, esté orientado a superar la desigualdad y destaque la potenciación de los pobres. Las recetas anticuadas de complementación dcl crecimiento rápido con el gasto social y redes de seguridad han demostrado ser insuficientes" El economista jefe del Banco Mundial, Nicholas Stern (2000) también sugiere: el crecimiento económico es mayor en paises donde la distancia entre ricos y pobres es más pequeña y el gobierno tiene programas para mejorar la equidad, con reformas agrarias, impuestos progresivos, y buen sistema de educación pública". Todos ellos van más allá del pensamiento único.

En este ambiente la falacia de "que no hay otra alternativa" resulta cada vez más insostenible en la América Latina actual. Por una parte a nivel internacional, como se advierte, empieza a haber una cada vez más activa búsqueda de alternativas diferentes. Por otro lado, hay en el escenario histórico presente países que han obtenido desempeños altamente exitosos en lo económico y lo social siguiendo vias distintas al pensamiento económico ortodoxo preconizado en la región, entre ellos: Canadá, varios países del sudeste asiático como Corea del Sur, Japón, los paises nórdicos: Noruega. Suecia, Dinamarca, Finlandia, Israel, Holan$\mathrm{da}$, y otros. Pero el argumento fundamental es la realidad misma, el pensamiento único ha producido resultados muy dudosos en América Latina. La CEPAL (2000), describe asi la situación social presente: "Hacia fines de los noventa las encuestas de opinión muestran que porcentajes crecientes de la población declaran sentirse sometidas a condiciones de riesgo, inse- 
guridad $e$ indefensión. Ello encuentra sustento en la evolución del mercado de trabajo, el repliegue de la acción del Estado, las nuevas formas institucionales para el acceso a los servicios sociales, el deterioro experimentado por las expresiones tradicionales de organización social, y las dificultades de la micro y pequeña empresa para lograr un funcionamiento que las proyecte económica y socialmente". Reflejando el desencanto con las políticas aplicadas en muchos casos, una encuesta masiva, el Latín Barómetro 2000, encuentra según describe Mulligan (2000) resumiendo sus resultados que "los latinoamericanos están perdiendo la fe el uno en el otro, asi como en sus sistemas políticos y en los beneficios de la privatización". Respecto a este último punto la encuesta informa que el $57 \%$ no está de acuerdo con el argumento de que la privatización ha beneficiado a su país. Para mucha gente, dice Marta Lagos directora de la encuesta, la privatización significa costos mas altos, y virtualmente el mismo nivel de servicios.

La población Latinoamericana no acepta la falacia de que no hay otras alternativas que estas que conducen necesariamente a altísimos costos sociales y al desencanto. Aparece en su imaginario con fuerza creciente que es posible, como lo han hecho otros países en el mundo, avanzar con las singularidades de cada país, y respetando sus realidades nacionales hacia modelos de desarrollo con equidad, desarrollo compartido, o desarrollo integrado, donde se busca armonizar las metas económicas y sociaies. Ello implica configurar proyectos nacionales que impulsen entre otros: la integración regional que puede ser un poderoso instrumento para el fortalecimiento económico de la región y su reinserción adecuada en el sistema económico global, el impulso vigoroso a la pequeña y mediana empresa, la democratización del acceso al crédito, el acceso a la propiedad de la tierra para los campesinos, una reforma fiscal orientada hacia una imposición más equitativa y la eliminación de la evasión, la puesta al alcance de toda la población de la tecnologia informática, la universalización de la cobertura en salud, la generalización de posibilidades de acceso a educación preescolar, y de finalización de los ciclos primario y secundario, el desarrollo del sistema de educación superior, el apoyo a la investigación científica y tecnológica, el acceso de toda la población a agua potable, alcantarillado y electricidad, la apertura de espacios que permitan la participación masiva en la cultura.

El marchar en dirección a metas de esta índole requerirá entre otros aspectos reconstruir la capacidad de acción del Estado, construyendo un perfil de Estado descentralizado, transparente, responsable, con un servicio civil profesionalizado, potenciar las posibilidades de aporte de la sociedad civil abriendo todas las vías posibles para favorecer su fortalecimiento, articular una estrecha cooperación de esfuerzos entre Estado y sociedad civil, desarrollar la responsabilidad social del empresariado, practicar políticas activas proempoderamiento y participación de las comunidades desfavorecidas. Todos ellos pueden ser medios formidables en una sociedad democrática, para movilizar las enormes capacidades de construcción y progreso latentes en los pueblos de América Latina. 


\section{Una mirada de conjunto}

Hemos visto como la existencia de falacias de extensa circulación que presentan una visión distorsionada de los problemas sociales de América Latina y de sus causas, y llevan a graves errores en las políticas adoptadas, es parte misma de los retrocesos y de la dificultad por mejorar la situación. No ayudan a superar la pobreza y la desigualdad, y por el contrario con frecuencia refuerzan estructuralmente visiones como: negar la gravedad de la pobreza, no considerar la irreversibilidad de los daños que causa, argumentar que el crecimiento económico sólo solucionará los problemas, desconocer la trascendencia del peso regresivo de la desigualdad, desvalorizar la función de las políticas sociales, descalificar totalmente a la acción del Estado, desestimar el rol de la sociedad civil y del capital social, bloquear la utilización de la participación comunitaria, eludir las discusiones éticas, y presentar el modelo reduccionista que se propone con sus falacias implícitas, como la única alternativa posible.

Estas visiones no son la causa única de los problemas, que tienen profundas raíces internas y externas, pero oscurecen la búsqueda de las causas, y pretenden legitimar algunas de ellas. Buscar caminos diferentes exige enfrentar y superar estas y otras falacias semejantes. Ello aparece en primer lugar como una exigencia ética. En el texto bíblico la voz divina reclama "No te desentiendas de la sangre de tu prójimo" (Levítico, 19:16). Las sociedades latinoamericanas y cada uno de sus miembros no pueden ser indiferentes frente a los infinitos dramas familiares e individuales que a diario surgen de la problemática social de la región. Asimismo deben ser muy autocríticas con las racionalizaciones de la situación y los autoengaños tranquilizadores. Al mismo tiempo atacar frontalmente las causas de la pobreza, no dando lugar a las negaciones y tergiversaciones, es trabajar por restituir ciudadanía a gran parte de los habitantes de la región cuyos derechos humanos elementales están de hecho conculcados por las carencias sociales. Por ultimo, frente a las falacias permítasenos elevar la voz de un gran escritor latinoamericano. Carlos Fuentes escribió (1995): "Algo se ha agotado en América Latina, los pretextos para justificar la pobreza".

\section{Bibliografía citada}
Altimir, Oscar (1994) Distribución del ingreso e incidencia de la pobreza a lo largo del ajuste. Revista de la CEPAL, No. 52, abril.

Berry Albert (1997). The income distribution threat in Latin America. Latin American Research Review. Vol. 32, No.2.

BID (1998). Informe de progreso económico y social. Washington, D.C.

Birdsall, Nancy, Ross, David, y Richard Sabot (1996). La desigualdad como limitación para el crecimiento económico. En Gestión y Política Publica, CIDE, México, Primer semestre.

Birdsall, Nancy (1998). Comentarios sobre el caso del Japón. Incluido en Emmerij L. y Nuñez del Arco J. (comp.). El desarrollo económico y social en los umbrales del siglo XXI, BID, Washington.

Birdsall Nancy, and Juan Luis Londoño (1997). Assets inequiality matters: an asessment of the World Bank approach to 
poverty reduction. American Economic Review. May.

CEPAL (2000). Panorama Social de América Latina 2000. Santiago de Chile.

Comisión Latinoamericana y del Caribe para el Desarrollo Social (1995). Informe sobre el desarrollo social. CEPAL, PNUD. BID.

Dunes, Nancy (2000), "Fees issue entangles US debt relief plan". Financial Times. October 18.

Fondo de Población Mundial. (2000). Informe sobre la población mundial 2000 . New York.

French Davis, Ricardo (2000). Reformar las reformas en América Latina. El País, Madrid. 30 de junio.

Fuentes, Carlos (1995). Introducción al informe de la Comisión Latinoamericana y del Caribe sobre el Desarrollo Social. CEPAL, PNUD, BID.

Havel, Vaclav (2000). Discurso inaugural de la Asamblea conjunta del FMI y el Banco Mundial. Praga.

Kusnetz, Simón (1970). Crecimiento económico y estructura económica. Editorial Gustavo Gill, Barcelona.

Latin Barómetro (2000). Encuesta 1999. Santiago de Chile.

Mintzberg, Henry (1996). Managing government. Government management. Harvard Business Review, May-June.

Mulligan, Mark (2000). Latin Arnerica sees optimism fade. Financial Times. May 10.

ONU. PNUD (2000). Informe sobre Desarroilo Humano 2000. New York.

Organización Mundial de la Salud (2000). The World Health Report 2000. Ginebra.

OPS. CEPAL (1998). Health, social equity and changing production patterns in Latin America and the Caribbean. Washington.
OPS (2000). Situación de salud en las Américas, Indicadores básicos 2000. Washington.

Pearlstein, Steve (2000). World Bank Rethinks poverty. September 13. Washington Post.

Pfaff, William (2000). The West globalization drive is proving a massive failure. International Herald Tribune, September 29 .

PNUD. Unión Europea (1999). Informe del proyecto "Estado de la regían". San José.

Rohatyn Felix (2000). The costs of globalization, Financial Times. September $17^{\text {th }}$.

PNUD (2000). Superar la pobreza humana. New York.

Sen, Amartya (1998). Mortality as an indicator of economic succes and failure. The Economic Journal, January.

Sen, Amartya (1998). Teorías del desarrollo a principios dcl Siglo XXI. Incluido en Emmerij L., Nuñez del Arco. J. El desarrollo económico y social en los um. brales del siglo XXI. BID, Washington.

Singer, Peter (1999). The Singer solucion to world poverty. The New York Times Magazine, September 5, New York.

Stalling, Barbara (1999). Conferencia, VII Congreso de Economistas de America Latina y el Caribe, Rio de Janeiro.

Stern, Nicholas (2000). Empowermente leads to enrichment. Financial Times, October 9 .

Stern, Nicholas (2000) En Washington Post, Steven Pearistein, World Bank rethinks poverty, September 13.

Stiglitz, Joseph (1998). Mas instrumentos y metas mas amplias para el desarrollo. Hacia un consenso post Washington. Reforma y Democracia, Revista del CLAD. No. 12, Caracas.

Taylor, Charles (1992). The ethics of authenticity. Hanvard University Press. 
Touraine, Alan (1997). Por una nueva política social. El País, 4 de agosto. Madrid.

Thomas, Vinod (2000). Why quality matters. The Economist, October $7^{\text {th }}$. London.

UNICEF (1992). Menores en circunstancias especialmente difíciles. Caracas.

Verrier, Roberto (1999). Declaraciones del Presidente de la Asociación de Eco. nomistas de América Latina y el Cari- be. VII Congreso de Economistas de América Latina y el Caribe. Rio de Janeiro, Septiembre 10.

Wolfensohn, James (2000). Declaraciones al diario francés Liberation. Paris, julio 10.

World Bank (1998). The state in a changing world. Washington.

World Bank (2000). The quality of growth, Washington, DC. 